\title{
Da educação: do jogo sociocultural e a inter-relação envolvendo modus vivendi e modus essendi
}

\author{
Luiz Carlos Mariano da Rosa
}

Programa de Pós-graduação em Educação, Universidade Gama Filho, Rua Manoel Vitorino, 625, 20740-280, Piedade, Rio de Janeiro, Rio de Janeiro, Brasil. E-mail: marianodarosaletras@uol.com.br

\begin{abstract}
RESUMO. O artigo em questão se detém na análise da educação por meio da mensagem do filme Coach Carter - Treino para a Vida (2005), que acena com o paradoxo da democratização do ensino e converge para as fronteiras que assinalam a função da escola e o papel do educador, sublinhando o jogo sociocultural e a inter-relação envolvendo modus vivendi e modus essendi que perfazem o referido processo.
\end{abstract}

Palavras-chave: escola, cultura, sociedade.

ABSTRACT. Education: of the sociocultural game and the inter-relationship involving modus vivendi and modus essendi. The article in question focuses on the analysis of education through the message of the movie Coach Carter - Training for Life (2005), which features the paradox of the democratization of education and converges to the boundaries that mark the function of the school and the role of the educator, stressing the sociocultural game and the inter-relationship involving modus vivendi and modus essendi that make up that process.

Keywords: school, culture, society.

\section{Introdução}

Richmond High School. Estabelecido na cidade homônima que perfaz um subúrbio industrial que contém aproximadamente 100 mil habitantes, situada na área da baía de São Francisco, no Estado da Califórnia, o Colégio Richmond integra o cenário das instituições escolares que detêm a responsabilidade de acolher a multidão dos alunos que não guardam nenhum tipo de identificação com o universo educacional, tendo em vista que, além da influência do contexto social, caracterizado, pois, pela violência ${ }^{1}$, a mudança morfológica instaurada no sistema de ensino entre as décadas de 1950 e 1990 promoveu uma reestruturação que sobrepôs à sua estabilidade restritiva, que trazia como base uma avaliação classificativa que penalizava os estudantes "culturalmente desfavorecidos", um processo de "democratização" que acena com o paradoxo que encerra a possibilidade de acesso à escola no tocante àqueles que pertenciam a categorias antes relegadas à exclusão e a manutenção das prerrogativas decorrentes do privilégio cultural dos mais favorecidos (ANDRADE; PEREIRA, 2007, p. 58).

Inserida em um contexto social que em função da omissão do Estado se mantém como refém do

${ }^{1}$ Richmond ocupa o segundo lugar neste aspecto no Estado da Califórnia, constituindo-se a oitava cidade mais perigosa dos Estados Unidos (ANDRADE; PEREIRA, 2007, p. 57) tráfico de drogas, o Colégio Richmond acena com a estigmatização das "escolas problemáticas", carregando nos seus estudantes os signos da exclusão à medida que a posição que ocupam no espaço sociocultural corresponde ao status dos pobres, negros e latinos no âmbito da sociedade americana, convergindo para eclipsar a relação que envolve a sua condição social e as representações simbólicas do universo escolar, cuja instituição, diante do hiato que se impõe entre a escola e a rua, torna-se "uma inutilidade completa" (ANDRADE; PEREIRA, 2007, p. 62).

Negro, ex-aluno do Colégio Richmond e morador do bairro onde a escola situa-se, Ken Carter $^{2}$, depois de se tornar um atleta renomado, cursar a universidade e se estabelecer como profissional bem-sucedido no ramo esportivo, assume o comando do time de basquete, percebendo que as possibilidades potencialmente disponíveis guardam raízes nas fronteiras do ginásio e da biblioteca, que acenam com a construção de dois tipos de capital, a saber, cultural e esportivo, que convergem para assegurar aos alunos-atletas os resultados materiais e simbólicos necessários para a promoção da sua integração social, desvelando o filme Coach Carter - Treino para a Vida $(\mathrm{COACH}$

${ }^{2}$ Samuel L. Jackson. 
CARTER, 2005)o paradoxo da democratização do ensino $^{3}$, que torna a escola um "depósito" de "estudantes condenados a viver uma escolaridade fictícia, um simulacro de currículo, uma modalidade de seleção altamente eufemística" (ANDRADE; PEREIRA, 2007, p. 58), à medida que imperceptivelmente engendra a exclusão escolar, além da influência que o educador pode exercer no tocante às desigualdades sociais se não instauradas perpetuadas pela instituição educacional, como no caso do técnico em questão, que usa o basquete, uma atividade altamente estimada na América, neste sentido, não treinando o time apenas para o jogo, mas também para a própria vida.

\section{Coach Carter: da educação para a vida (do jogo sociocultural)}

Caracterizando a vida sociocultural das comunidades humanas, sem exceção, a educação ${ }^{4}$, atividade estruturalizante que se impõe entre o ser humano e o mundo instrumentalizando a gestação da realidade, perfaz, em última instância, as referencialidades do arcabouço do conhecimento, que traz como conteúdo, sob o signo da historicidade da razão, um conjunto de práticas, teorias, instituições, valores materiais e espirituais, enfim, um sistema de símbolos, em suma, produzido na construção da existência, que institui modos de viver e pensar, condutas, comportamentos, e caracteriza-se como arbitrário à medida que a sua institucionalização escapa à estruturalidade de qualquer razão objetiva, universal, segundo a leitura de Bourdieu, que interpreta o fenômeno que produz a sua legitimação como a imposição das forças que interagem no contexto de uma sociedade conferindo aos códigos das experiencializações e vivencialidades dos segmentos dominantes primazia, em detrimento de outros que não alcançam o horizonte que encerra a verdade institucionalizada pela instauração em questão, convergindo para a emergência da "violência simbólica" que se impõe ao processo formativoeducacional pela capacidade da autoridade pedagógica de transmitir os conteúdos de um arbitrário cultural dissimuladamente, desenvolvendo, "assim, uma atividade reprodutora e legitimadora das desigualdades sociais, embora

\footnotetext{
${ }^{3}$ Conclusão que emerge pelo pensamento do sociólogo francês, Pierre Bourdieu, cujo argumento, em relação ao fenômeno em questão, assinala que se antes a instituição escolar instaurava a eliminação no início do processo formativoeducacional, as mudanças estruturais que ocorreram em função da influência que envolve a "crença no valor dos títulos e conhecimentos escolares" convergem para ocultar a referida operação, diluindo-a no tempo e postergando-a para "os níveis subsequentes da escolaridade" (ANDRADE; PEREIRA, 2007, p. 58).

${ }^{4}$ Do lat. "educe", "fazer sair", "educar", "edùco,as,ávi,átum,áre", que significa "criar [uma criança]; nutrir; amamentar, cuidar, educar, instruir, ensinar"
} (DICIONÁRIO..., 2009) como uma relação formalmente igualitária" (MARIANO DA ROSA, 2009, p. 53).

\begin{abstract}
Nesse sentido, Coach Carter mostra clara e empiricamente a proposição - que a escola insiste em ignorar - expressa por Pierre Bourdieu e Jean Claude Passeron em "A Reprodução": os arbitrários pedagógicos são recebidos de forma desigual pelas distintas classes e frações de classe, ou, em outras palavras, o reconhecimento e a incorporação das exortações pedagógicas dependem da correspondência entre o conteúdo da mensagem e as condições sociais e o modo de vida dos receptores [...] (ANDRADE; PEREIRA, 2007, p. 61, grifo do autor).
\end{abstract}

À experiência sociocultural da juventude do Colégio Richmond se impõe a percepção de que as informações, as normas e as noções transmitidas pela instituição escolar não têm valor diante da violência urbana, à medida que não guarda condição de preparar para o enfrentamento dos acontecimentos que se sobrepõem ao suposto domínio com o qual porventura acenam em um contexto no qual se descobrem privados, enfim, das "redes sociais de segurança" e dos "mecanismos intelectuais de previsibilidade e cálculo", tendo em vista a precariedade que carrega a vida neste tipo de ambiência, que encerra uma escola que "acrescenta, à fragilidade social, a incerteza propriamente escolar característica de estudantes encurralados numa lógica incompreensível para eles (vão à escola, mas não sabem os motivos)" (ANDRADE; PEREIRA, 2007, p. 61).

A síntese da desigual trama material e simbólica entre a escola e a rua se vê na escolarização, que, sentida na pele dos jovens na forma de cotidianos repletos de rotinas áridas e códigos inextrincáveis (álgebra, geometria, história), termina, para esses jovens, em desemprego. Por sua vez, como chamariz ilusório, a rua potencializa o usufruto das coisas capazes de conferir sentidos a vidas que só se nutrem do presente e do instante fugidio - dinheiro no bolso, consumo, a segurança fictícia das gangues (ANDRADE; PEREIRA, 2007, p. 62).

Nesta perspectiva, pois, longe de se circunscrever ao âmbito da perspectiva objetivista, que se fundamentaliza no pressuposto de que a realidade social é constituída de um conjunto de normas e regras que mantém, da mesma forma que as leis físicas, uma relação de independência diante da consciência, e escapando da ótica subjetivista, que advoga que tudo o que provém da consciência se exime a uma investigação experimental, importa que o educador, sob o horizonte que implica a práxis pedagógica, instrumentalize o desvelamento das raízes que se não determinam influenciam as vivencialidades inter-individuais, interpessoais, intersubjetivas, as quais, escoando do arcabouço da 
apreensão do sujeito ${ }^{5}$, embora jamais se deixem recuperar experiencialmente, sobrevivem parasiticamente nas camadas subterrâneas do solo da sociabilidade, subsidiadas pelo caráter aparentemente imutável da sua estruturalidade, emergindo no processo de construção do conhecimento à medida que converge para intencionalizar, nas fronteiras do "eu-tu", o compartilhamento de ideias, valores e práticas do sítio arqueológico do conhecimento, em síntese, do arcabouço formativo-educacional, enfim, cujo paradoxo, no âmbito das instituições escolares "situadas em meios sociais como o ambiente de Coach Carter é o de não poder oferecer a possibilidade da integração social a esses jovens cujos capitais são bastante reduzidos" (ANDRADE; PEREIRA, 2007, p. 62, grifo do autor).

Neste contexto perspectivacional, por meio da práxis pedagógica, ao educador se impõe, pois, guardando o sentido que a sua existência encerra como tal, a percepcionalidade da maneira pela qual as condicionalidades objetivas de existencialidade são interiorizadas, cujas disposições adquiridas, transformadas em "naturais", estruturalizando a subjetividade, tornam-se a instrumentalidade de interiorização da exterioridade, conforme assinalam os rastros de Bourdieu que, nesta acepção conceitual, identifica habitus ${ }^{6}$, que, em suma, de acordo com a sua leitura, engendra um sentimento de identidade sociocultural, tendo em vista que a incorporação das atitudes que carrega institui a inclusão do indivíduo em um determinado grupo social, um espaço específico estruturalizado por relações objetivas, segundo uma lógica própria, que concentra recursos de um "capital simbólico" (BARAQUIN; LAFFITTE, 2004, p. 78).

A primeira providência tomada pelo técnico no momento de sua chegada à escola foi a de estabelecer regras e normas a serem observadas pelos alunos atletas para jogarem no time de basquete. As regras e normas diziam respeito, entre outras coisas, ao cumprimento de horários, uso de terno e gravata nos dias de jogos, manutenção de notas mínimas nas disciplinas acadêmicas, frequência diária às aulas, assento nas primeiras filas das salas, realização de trabalho voluntário, tratamento mútuo respeitoso, etc. Tudo isto estava especificado em um documento a ser assinado, obrigatoriamente, por

\footnotetext{
5 Ou "agente", segundo a perspectiva bourdieusiana, que acenando com o sentido literal, "aquele que age", se impõe para "designar os indivíduos participando do processo de interação social, que pressupõe uma posição antagônica em relação à concepção do sujeito 'livre', detentor da capacidade de transformar o mundo através da instrumentalidade da razão" (MARIANO DA ROSA, 2009, p. 56).

'Do latim "maneira de ser", refere-se à "capacidade que permite a um indivíduo, no momento certo e como que por instinto, agir de forma correcta [sic] e
} apropriada a esta ou aquela esfera" (BARAQUIN; LAFFITTE, 2004, p. 78-79). estudantes atletas, família e técnico (ANDRADE; PEREIRA, 2007, p. 62).

Exortando os seus alunos-atletas a superarem a condição de ambiguidade que carregam em virtude do papel de "estudantes que não estudam" que cumprem no âmbito do Colégio Richmond, Carter elabora um trabalho pedagógico que enfatiza o privilégio que envolve o pertencimento a uma "organização" formal capaz de propor horizontes que se sobreponham aos atrativos das gangues, a saber, o time de basquete, que representa "o papel institucional que a escola não consegue desempenhar", convergindo para implicações que guardam correspondência com o sentimento de honra que, na esfera das sociedades desertificadas, que abrangem desde Richmond até o complexo favelístico do Brasil, se mantém relacionado à participação nas atividades coletivas institucionais, organizadas pelas gangues, no caso em questão, à medida que neste contexto o sentido da vida humana está associado a uma ocupação, sem a qual é instaurada a morte socioeconômica e cultural do sujeito.

[...] As gangues tiram partido do ethos reinante em sociedades nas quais o trabalho é tudo e não ter trabalho significa a morte social. No lusco-fusco dos valores, dar duro num ponto de venda de narcóticos é igual a mourejar numa fábrica ou escritório, só que incomparavelmente mais rentável (ANDRADE; PEREIRA, 2007, p. 64, grifo do autor).

Incorporando, mais do que a tendencialidade embora também -, mas a fronteira dialogal que o seu procedimento propõe, convém que o educador guarde a sua consciência sócio-histórica do anestesismo ideológico e da anorexia intelectual da pós-modernidade, mantendo-a sensibilizada diante do acontecimento da vivencialidade humana, à altura da percepcionalidade das singularidades que interseccionam e simultaneamente diferencializam a temporalidade imediata da pretérita, e dissecando a corporalidade desta, quantificar e qualificar os eventos, acenando para um horizonte de sentido no tocante ao processo formativo-educacional, conforme vislumbra Carter por meio da sua proposta pedagógica que, baseada na fórmula "ginásio + biblioteca", converge, em virtude das imposições que carrega, para as fronteiras que envolve da exteriorização da respeitabilidade burguesa à responsabilidade e ao ingresso no universo dos adultos, representando para a juventude em questão a possibilidade de escapar ao destino mais provável, tanto quanto, por essa razão, mais objetivo, a saber, a delinquência (ANDRADE; PEREIRA, 2007, p. 64). 
Nesta perspectiva, pois, a mensagem do filme em questão acena com a possibilidade de construir uma situação pedagógica que seja capaz de dialogar com a lógica do sistema que, em nome da práxis "reproducionista", mantém a instituição escolar como refém dos mecanismos de exclusão social, guardando, simultaneamente, a paradoxal tendência que carrega por meio do seu exercício de possibilitar a emergência de um arcabouço capaz de reduzir os efeitos da "violência inerte" das estruturalidades socioculturais (ANDRADE; PEREIRA, 2007, p. 65), convergindo para as fronteiras que assinalam uma problematicidade no tocante à inter-relação envolvendo a conformação ao seu modus vivendi e o horizonte da autotransformação, que se refere ao modus essendi, como pressupostos do processo formativo-educacional que, no contexto sóciohistórico brasileiro, demanda uma análise que não expõe senão as raízes ideológicas que o caracterizam desde a sua instauração, perfazendo uma silhueta identitária cuja concepção ainda se detém no âmbito da mentalidade colonialista, permanecendo relegada à condição de "arma civilizatória", negligenciando um dos seus aspectos fundamentais, a saber, a preparação para o exercício da cidadania, que, afinal, implica uma correlação de eventos que concorre, em suma, para o desenvolvimento da nação.

\section{Da educação: da inter-relação envolvendo Modus Vivendi e Modus Essendi e a ‘Conjugação’ da responsabilidade}

Emergindo da inter-relação de fatores que envolvem a fruição dos direitos civis e políticos e o cumprimento de deveres diante de um Estado, à circunscrição conceitual de cidadania, elemento dos princípios fundamentais que remetem à constitutividade do Estado Democrático de Direito, impõe-se um diálogo que reclama a comunicação de conhecimentos, o aperfeiçoamento de capacidades morais e intelectuais e o desenvolvimento da personalidade do indivíduo por meio do ensino dirigido ou de exemplos espontâneos, formal ou informalmente, conforme $\mathrm{o}$ pressuposto da Constituição da República Federativa do Brasil ${ }^{7}$, que diz: "A educação, direito de todos e dever do Estado e da família, será promovida e incentivada com a colaboração da sociedade, visando ao pleno desenvolvimento da pessoa, seu preparo para o exercício da cidadania e sua qualificação para o trabalho" (BRASIL, 2002, p. 173).

"Processo de desenvolvimento da capacidade física, intelectual e moral da criança e do ser humano em geral, visando à sua melhor integração individual

7 Artigo 205, Seção I (Da Educação), Capítulo III (Da Educação, Da Cultura e Do Desporto), do Título VIII (Da Ordem Social). e social", a educação desenha a interseccionalidade de dois aspectos que demandam oposição e complementaridade, a saber, a inter-relação do sentido que reclama a conformação ao "modus vivendi" de um arcabouço social e da perspectiva que acena para o horizonte da autotransformação, que se refere ao modus essendi, tendo em vista que, guardando a pretensão de conferir aptidão à personalidade em face da sua necessidade de sobreviver e viver em sociedade, engendra a proposta que converge para a possibilidade de instrumentalizar a autonomia individual, tanto quanto a mudança sócio-histórica.

Recorrendo à imagística do eixo conceitual proposto por Hannah Arendt na investigação do processo educacional, a saber, natalidade, que o caracteriza, pois, como forma de inserção de um ser vivo - contrapondo a vida humana, bios, àquela que outros seres, como plantas e animais, desfrutam, zoe (DUARTE, s/d, p. 85) - em um ambiente préexistente, se à família cabe, em um primeiro momento, o papel em questão, que objetiva, enfim, torná-lo um de seus membros, à escola se impõe o sentido que reclama a conformação ao modus vivendi de um arcabouço social que, inter-relacionado idealmente à perspectiva que acena para o horizonte da autotransformação, tende a sobrepujá-lo, afinal.

De acordo com tal leitura, emerge, pois, como um dos principais problemas do processo formativoeducacional, a questão que envolve a sua incapacidade de cumprir as pretensões conjugadas no âmbito da sua construção identitária, principalmente quanto da autotransformação, inabilidade esta que guarda relação com os liames ideológicos que, segundo a análise do professor José de Souza Martins ${ }^{9}$, torna a instituição de ensino do Brasil refém de um sistema que a mantém

atrelada aos pressupostos da guerra cultural e pedagógica contra as famílias atrasadas, supostos redutos da ignorância, redutos de uma cultura rústica e pré-moderna que perturbaria a inclusão das novas gerações no mundo presumivelmente mais desenvolvido da razão, da ciência e da tecnologia (MARTINS, 2008, p. 6).

"Instrumento de guerra civilizadora", eis a característica que o processo formativo-educacional brasileiro carrega desde os primórdios, quando emergiu a necessidade de desestruturar a cultura nativa, utilizando o recurso da catequização que

\footnotetext{
${ }^{8}$ Ferreira (1986, p. 619).

${ }^{9}$ Professor titular de Sociologia da Faculdade de Filosofia da USP e autor de, entre outros títulos, "A aparição do Demônio na Fábrica”, Editora 34.
} 
objetivava, em suma, a desconstrução das sociedades primitivas existentes no território brasileiro na época do seu descobrimento, tendência que, segundo José de Souza Martins, esconde-se sob a inaptidão da educação de engendrar o fenômeno da socialização que se impõe em um contexto que denuncia, por um estudo da Fundação Itaú Social, que $70 \%$ do desempenho escolar depende da família, cabendo à escola $30 \%$. Escolaridade dos pais, renda familiar, moradia, acesso aos bens culturais, eis os fatores determinantes que geram condições que implicam vantagem ou desvantagem para o educando, guardando relação com os índices educacionais, econômicos, sociais e culturais, pré-requisitos inatingíveis para uma significativa parcela das famílias brasileiras (MARTINS, 2008, p. 6). Conclusão:

Uma escola obsessivamente voltada para a sua própria razão e no geral incapaz de dialogar com as famílias que o desenvolvimento desigual da sociedade e da economia brasileiras deixou confinadas no atraso e nas decorrentes insuficiências econômicas, sociais e culturais. Em boa parte, se a escola brasileira tendo $\mathrm{m}$ clareza quanto a suas funções como agência de educação das novas gerações, tem também imensas dificuldades para compreender sua inevitável função como simultânea agência de ressocialização de crianças e jovens cuja inserção familiar os obriga a viver tempos sociais descompassados e conflitantes (MARTINS, 2008, p. 6).

Se a "igualdade de condições para o acesso e permanência na escola", segundo a Constituição da República Federativa do Brasil ${ }^{10}$ (BRASIL, 2002, p. 174), é um dos princípios da base do exercício do ensino, ao resultado da revisão da literatura sobre o desempenho escolar promovida pela Fundação Itaú Social se impõe a crítica de Pierre Bourdieu em relação à "democratização" do sistema educacional, tendo em vista o caráter paradoxal que encerra, pois embora possibilite "o direito ao acesso à escola por alunos de categorias antes excluídas, mantém as prerrogativas decorrentes do privilégio cultural dos mais favorecidos" (ANDRADE; PEREIRA, 2007, p. 58).

A escola exclui, como sempre, mas ela exclui agora de forma continuada, a todos os níveis de curso, e mantém no próprio âmago aqueles que ela exclui, simplesmente marginalizando-os nas ramificações mais ou menos desvalorizadas. Esses 'marginalizados por dentro' estão condenados a oscilar entre a adesão maravilhada [...] e a resignação aos seus veredictos, entre a submissão ansiosa e a revolta impotente.
[...] Eles são obrigados pelas sanções negativas da Escola a renunciar às aspirações escolares e sociais que a própria escola inspira; são obrigados, por assim dizer, a engolir o sapo, e por isso levam adiante sem convicção e sem pressa uma escolaridade, que sabem não ter futuro (BOURDIEU, 2003, p. 485).

Se desenvolvimento, sob a perspectiva de uma leitura abrangente, designa os meios de erradicação da pobreza, de elevação da receita e de intensificação das oportunidades de emprego, destacando-se como um dos obstáculos que se impõe à sua construção as deficiências do capital humano em virtude dos baixos investimentos na educação, qual não é a influência do processo formativo-educacional que, embora engendrado pelas inter-relações dos pressupostos do contexto geopolítico, socioeconômico e histórico-cultural da sociedade, inclinando-se, pois, sob o signo de uma relação formalmente igualitária, para a reprodução e legitimação das desigualdades sociais, insinua a possibilidade de mudança, guardando o sentido que Arendt desvela ao atribuir à escola o papel de realizar a transição entre "o espaço íntimo da família e o mundo público do exercício da cidadania” (CÉSAR, s/d, p. 37).

Uma das três condições que se impõe ao desenvolvimento, segundo o sociólogo Alain Touraine ${ }^{11}$, além do "componente" designado como "classes sociais", ou "coalizão de forças definidas por seus conflitos", e da "crença na razão" (TOURAINE, 2003, p. 11), a cidadania emerge como elemento fundamental, tendo em vista que

o desenvolvimento é sempre de um povo, de um território com suas instituições e sua cultura, pois sem cidadania cada grupo se fecha sobre si mesmo e a competição ou os conflitos entre as partes do conjunto acabam por exauri-lo, como se vê em muitos países africanos (TOURAINE, 2003, p. 11).

Se à Educação, segundo a perspectiva de Arendt, cumpre instaurar "o deslocamento do espaço privado da individualidade para o espaço público do bem comum" (CÉSAR, s/d, p. 38), a ênfase dos movimentos de psicologia quanto à questão que envolve a ideia de indivíduo e de individualidade, sintomática da crise da política no mundo moderno, engendrando o fenômeno da "infantilização generalizada", contribui para a perda das referencialidades de percurso do processo formativo-educacional, que não pode prescindir do diálogo com os valores arquetípicos da cidadania.

${ }^{11}$ Diretor da Escola de Altos Estudos em Ciências Sociais, em Paris, e autor de "A Crítica da Modernidade", Editora Vozes. 
Se as famílias, cuja organização e cuja cultura as distancia dos requisitos da escola na prévia preparação de seus filhos, estão enviando à escola crianças e adolescentes distantes dos requisitos culturais pela escola definidos, por outro lado a escola se fechou como agência de socialização e nesse sentido também ela está significativamente atrasada em relação ao que é um direito da família (MARTINS, 2008, p. 6).

Se a tarefa da Educação, segundo a análise de Arendt, é difícil e crítica, tendo em vista a sua contínua exposição "à redefinição de limites entre o público e o privado", responsabilidade, pois, é a noção que emerge, cuja perda, caracterizando as relações entre pais e filhos e entre professores e alunos, remete ao sentido que envolve tanto as garantias da conservação do mundo quanto as condições para sua efetiva transformação política (DUARTE, s/d, p. 87-88).

\section{Considerações finais}

Acontecimento complexo que escapa ao fenômeno da absoluta objetificação, a realidade que se impõe aos pressupostos pedagógicos, reclamando a investigação, se não da totalidade do campo científico, no qual emerge inescapavelmente como arcabouço paradigmático, das ciências humanas, especificamente, a saber, a pessoa humana, pois, que como a própria referencialidade destas, caracterizase, em síntese, por uma logística que, interseccionando diversas fronteiras do conhecimento, em nenhuma delas se esgota, trazendo como justificativa da sua singularidade o conjunto, que o torna um lugar de convergência autoexplicativa, condição sine qua non da sua existencialidade, tanto quanto das dimensões do saber cuja rede de relações para si, em si, de si constrói, alcança relevância a necessidade que se impõe no tocante ao estímulo que envolve da capacidade de raciocínio e julgamento à capacidade reflexiva, as competências do pensar, em suma, tendo em vista que o fenômeno da internalização dos meios cognitivos de compreensão e transformação do mundo, assim como do aprendizado da cultura, se detém nas fronteiras da escola, a despeito de uma conjuntura sociocultural que acena para a perda do horizonte de um mundo de significações, práticas e valores compartilhados, que emerge no âmbito do processo educacional, que carrega um sentido que se coloca sob o signo da interrogação, como contributo ao "progresso", não do pensamento, mas da "irreflexão", uma das principais características da contemporaneidade, que, segundo Arendt, emerge como "a imprudência temerária ou a irremediável confusão ou a repetição complacente de 'verdades' que se tornaram triviais e vazias" (CARVALHO, s/d, p. 25).

[...] Como educar numa ordem social em que o que há em comum são os interesses particulares em conflito? Que critérios podem ser evocados para a escolha curricular, por exemplo, dentre a diversidade de tradições, valores, interesses que compõem uma sociedade cada vez mais fragmentada? Como estabelecer critérios comuns e públicos de renovação e escolha curricular numa sociedade que se concebe como o somatório de interesses particulares em tensa competição por espaço e legitimidade? (CARVALHO, s/d, p. 22).

A perda de estabilidade que envolve o conhecimento, tanto quanto os seus potenciais portadores - os educadores -, eis a leitura que Arendt propõe para a crise em questão, convergindo, em suma, para pôr em relevo o esboroamento da "autoridade legítima", que guarda diferenças em relação às condições impostas pela sua ausência e pela sua ilegitimidade, fenômeno que se insinua no mundo moderno desde o âmbito pré-político, que abrange lar e escola, acenando para a diluição das fronteiras que se impõem entre as esferas pública e privada, que, respectivamente, remetem à distinção, quanto à vida do cidadão, entre o que lhe é comum [koinon] e o que lhe é próprio [idion], cuja consequência não é senão a substituição de um mundo de significações, práticas e valores compartilhados por uma realidade que advoga a gestão de interesses particulares (CARVALHO, s/d, p. 21).

Se a precariedade das relações estabelecidas entre a instituição escolar e o seu entorno social guarda correspondência com os fatores que emergem interrelacionados da posição que o Colégio Richmond ocupa a sete anos na escala de rendimento escolar da Califórnia, detendo o seu mais baixo grau, caracterizando a improdutividade geral do estabelecimento, em uma das cenas do filme Coach Carter a desesperança é exposta pelo professor e técnico Carter pela estatística que mostra que 50\% dos estudantes não se formam, constituindo apenas $6 \%$ dos formados aqueles que ingressam na universidade, perfazendo, nessa região, 33\% dos homens negros entre 18 e 24 anos o contingente prisional, convergindo para a conclusão de que em Richmond há " $80 \%$ mais chance de um jovem ir para a prisão do que para a universidade", segundo a sua fala, que alerta: "[...] Olhem para as vidas de seus pais e perguntem: quero mais do que isto?" (ANDRADE; PEREIRA, 2007, p. 60).

É nessa fronteira que o pensamento do educador deve se deter, procurando escapar, pois, à 
tendencialidade que os assedia e, embora não inteiramente imune, desnudar os mecanismos engendrantes dos valores que fundamentalizam, em suma, as inter-relações sociopsicológicas neste universo simbólico do mundo humano, no qual, em virtude da sua essencial não-imutabilidade, a absolutização do conceito, que torna-se núcleo das "pré-conceitualidades", não sinonimiza senão racismo, como identifica a leitura bourdieusiana:

[… É preciso ter em mente que não há um racismo, mas vários racismos: há tantos racismos quantos grupos que precisem justificar sua existência como tal, o que constitui a função invariante dos racismos.

Parece-me muito importante analisar as formas de racismo que, sem dúvida, são as mais irreconhecíveis, e portanto as mais raramente denunciadas, talvez porque os que comumente denunciam o racismo possuam certas propriedades que levam a esta forma de racismo. Estou pensando no racismo da inteligência.

[...] Este racismo é próprio de uma classe dominante cuja reprodução depende em parte da transmissão do capital cultural, capital herdado que tem como propriedade o fato de ser um capital incorporado, e portanto aparentemente natural, inato. $\mathrm{O}$ racismo da inteligência é aquilo através do que os dominantes visam a produzir uma 'teodicéia do seu próprio privilégio', como diz Weber, isto é, uma justificativa da ordem social que eles dominam... (BOURDIEU, 1983, p. 205-206).

Se da contemplação do objeto de "pesquisa" à incorporação da indumentária metodológica ao educador não se permite a possibilidade de escapar aos nós simbólicos da rede de conhecimento, nem tampouco da logística institucionalizada neste contexto, importa um movimento no sentido de, a partir deles, capturar os liames da existência, se para ela converge o seu esforço, envolvendo-se com a dinamicidade da vivencialidade humana, sendo capaz de assumir o papel de "o outro", dialogando simultaneamente pela multiplicidade de perspectivas que caracteriza o fenômeno que se convenciona identificar como realidade, tendo em vista que é não menos do que a sua gestação que se põe como proposta para a práxis pedagógica, que implica, enfim, a auto-afirmação dos "eus" em seu núcleo por meio do sempre inescapável âmbito do "eu-tu", conforme a conclusão que se impõe pelo resultado alcançado pelo professor e técnico Carter no filme em questão:

A primeira impressão do técnico Carter, ao chegar ao ginásio do Colégio Richmond, foi a de que os rapazes eram zangados e assustados, além de precisarem de disciplina. O triunfo do técnico Carter, expresso no inesperado êxito dos seus alunos atletas - "Vim aqui para treinar um time de basquete e tenho agora alunos, vim para treinar garotos e vocês agora são homens" -, se deu no combate ostensivo à indisciplina, no enfrentamento diário aos medos partilhados por aqueles jovens habitantes de uma zona social difícil [...] (ANDRADE; PEREIRA, 2007, p. 65).

Nesta perspectiva, pois, eis o horizonte para o qual converge a leitura do filme Coach Carter acerca do papel do educador que, em um contexto social semelhante àquele no qual o Colégio Richmond estava inserido, geralmente dispõe de duas alternativas, a saber, "desiludir de vez os estudantes ao contar-lhes a verdade de suas improváveis condições de sucesso, ou, então, narrar-lhes uma fábula muito convincente sobre coisas que nunca lhes acontecerão e cuja serventia não é outra senão justificar a si mesmo, o professor, e legitimar a escola" (ANDRADE; PEREIRA, 2007, p. 65), construindo o professor e técnico Carter um viés que acena com a rejeição ao modo de operação da escola, em relação à sua indiferença, não a relegando, contudo, às fronteiras do desencantamento, à medida que explicita a lógica do sistema, contraposto aos seus alunos-atletas, propondo uma aliança entre a biblioteca e o ginásio que funcione em seu benefício, tornando, dessa forma, possível o improvável, e real o nunca sonhado (ANDRADE; PEREIRA, 2007, p. 65).

Impor materialidade às forças que se conjugam sob a penumbra da abstracionalidade, desnudando os imperceptíveis liames que as inter-relacionam no processo de gestação da realidade socioeducacional;

Não se permitir seduzir pela tendencialidade tecnicista da razão instrumental que, unilateralizando os pressupostos da práxis pedagógica, converge para a absolutização dos veículos que carregam a capacidade de quantificar uma determinada realidade, superestimando as macroestruturas em detrimento dos nós que as arrastam consigo, cujas raízes, demandando interpretação, reclamam para si o peso do sentido;

Envolver-se com o movimento das vivencializações humanas a fim de que o seu procedimento pedagógico renuncie aos atalhos da autocentralidade teórica, não se pretendendo como um fenômeno acabado, mas, aceitando o risco da indeterminação que da complexidade da existência emerge, dialogar com o precipício do absurdo através do arcabouço da inter-trans-multidisciplinaridade.

Concernente às formas por meio das quais o educador, no processo de planejamento, pode contribuir com a práxis pedagógica, eis as fronteiras com as quais a mensagem do filme Coach Carter dialoga: 
Conferir visibilidade às estruturalidades que, determinando a dinamicidade das vivencialidades humanas e condicionando o funcionamento da sociabilidade, escapam à circunscrição da perspectivação dos sujeitos, ou "agentes", do processo;

Construir uma perspectivação que interseccionalize a dimensão subjetiva, núcleo de convergência da percepcionalidade intelecto-afetiva-volitiva, consciencial, em suma, tanto quanto da tendencialidade orgânica, e a estruturalidade objetiva, capturando a relação entre o que se impõe como realidade no campo interpessoal e como "oque-se-impondo" propõe para um ente que jamais se permite o sequestro do "é", auto-afirmando-se desde sempre como "ser-sendo";

Desenhar rastros de consciencialidade que descontruam o beco-sem-saída da imutabilidade $\mathrm{da}$ logística estrutural $\mathrm{da}$ realidade sociopsicológica, acenando para a possibilidade de transformação que o umbral da "territorialidade do saber", científico e/ou filosófico, incorpora, desde que, transpondo as suas fronteiras, os entes sociais pretendam-se como "agentes", mais do que sujeitos, do processo formativo-educacional (COACH CARTER, 2005).

\section{Referências}

ANDRADE, M. C. L.; PEREIRA, G. R. M. Coach Carter ou a segunda chance dos excluídos do interior. Revista Educação Especial, v. 5, p. 56-65, 2007.

BARAQUIN, N.; LAFFITTE, J. Dicionário de Filósofos. Tradução Pedro Elói Duarte. Lisboa: Edições 70, 2004. (Coleção Lexis).

BOURDIEU, P. Questões de Sociologia. Rio de Janeiro: Marco Zero, 1983.

BOURDIEU, P. A Miséria do Mundo. 5. ed. Petrópolis: Vozes, 2003.

BRASIL. Constituição da República Federativa do Brasil: promulgada em 5 de outubro de 1988. Rio de Janeiro: Expressão e Cultura, 2002. p. 331, v. 20, Coleção Páginas Amarelas/Texto Integral).
CARVALHO, J. S. F. A crise na educação como crise da modernidade. Revista Educação Especial, v. 4, n. 4, p. 16-25, s/d.

CÉSAR, M. R. A. A educação num mundo à deriva. Revista Educação Especial, v. 4, n. 4, p. 36-45, s/d.

COACH CARTER. Treino para a Vida. Direção: Thomas Carter. Produção: David Gale; Brian Robbins; Michael Tollin. Intérpretes: Samuel L. Jackson; Ryan B. Adams; Ashanti; Adrienne Bailon; Ray Baker; Texas Battle; Michelle Boehle; Rob Brown e outros. Roteiro: Mark Schwahn e John Gatis. Música: Trevor Rabin. EUA: Paramount Pictures, 2005. 1 DVD (136 min.), widescreen, sonoro, colorido. Baseado em fatos reais.

DICIONÁRIO Houaiss. Dicionário da Língua Portuguesa. Disponível em: <http://www.houaiss.uol. com.br/busca.jhtm?verbete $=$ educa $\% E 7 \% E 3 o>$. Acesso em: 7 jan. 2009.

DUARTE, A. Educação: entre a tradição e a ruptura. Revista Educação Especial, v. 4, n. 4, p. 84-89, s/d.

FERREIRA, A. B. H. Novo Dicionário Aurélio da Língua Portuguesa. 2. ed. rev. e ampl. Rio de Janeiro: Nova Fronteira, 1986.

MARIANO DA ROSA, L. C. Da Essencialização da Realidade. Revista Filosofia Capital, v. 4, n. 8, 2009. Disponível em: <http://www.filosofiacapital.org/ojs-2.1.1/ index.php/filosofiacapital/article/view/89>. Acesso em: 7 jan. 2009.

MARTINS, J. S. Quem não fez a lição? O problema do aprendizado não está no descompasso entre os pais e a escola, mas no contrário. O Estado de S. Paulo, São Paulo, 2 nov. 2008. (Aliás J6, p. 6).

TOURAINE, A. Decepção e esperança na América Latina. Tradução Rubia Prates Goldoni. Folha de S. Paulo, São Paulo, p. 11, 28 set. 2003. (Mais!)

Received on March 13, 2011

Accepted on June 29, 2011.

License information: This is an open-access article distributed under the terms of the Creative Commons Attribution License, which permits unrestricted use, distribution, and reproduction in any medium, provided the original work is properly cited. 